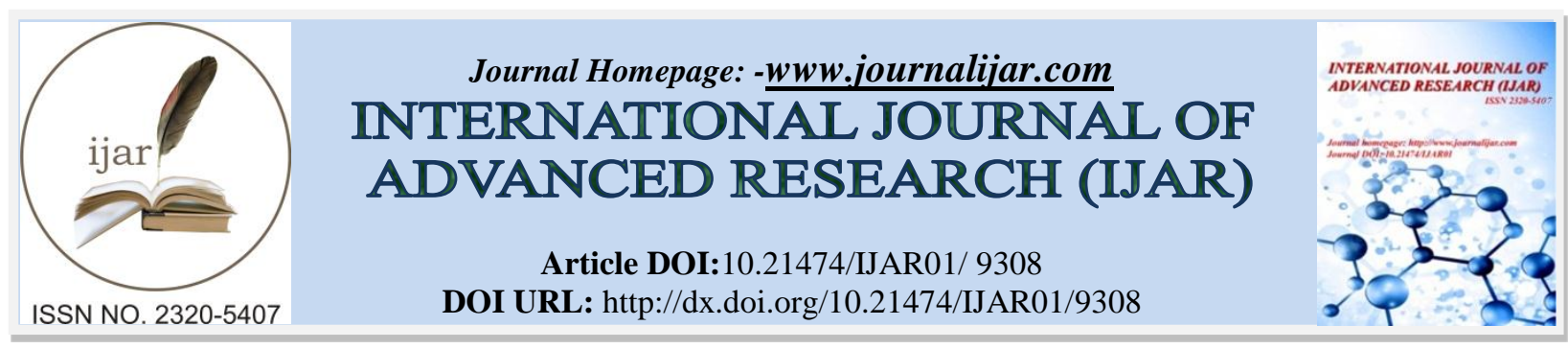

RESEARCH ARTICLE

\title{
COMPARATIVE STUDY OF OPEN VERSUS VARIOUS LAPAROSCOPIC MODALITIES IN CONGENITAL INGUINAL HERNIA.
}

Dr. Bhavana Verma ${ }^{1}$ and Dr. Anurag Anand ${ }^{2}$.

1. Lecturer, department of surgery, S.N. Medical College, Agra, U.P.

2. Junior resident, department of surgery, S.N. Medical College, Agra, U.P.

\section{Manuscript Info}

Manuscript History

Received: 15 April 2019

Final Accepted: 17 May 2019

Published: June 2019

\section{Abstract}

Copy Right, IJAR, 2019,. All rights reserved.

\section{Introduction:-}

The development of minimally invasive surgery has probably been the biggest revolution in surgical practice in last three decades, which has gone through a period of rapid development during last 20 years.

These minimal access techniques have changed the approach to many surgical procedures, one of such changing procedure is laparoscopic hernia repair in children which is receiving widespread interest from many general surgeons.

The present study has been done to report the results of randomized trial comparing laparoscopic hernia repair (trans-abdominal ring closure) versus conventional herniotomy in children in terms of recovery, complications and recurrences.

\section{Material and methods:-}

This study was conducted on 90 patients of up to 14 years of age group, coming to surgical ward through surgical out-patient department of S.N. Medical College and Hospital, Agra, admitted as case of inguinal hernia.

\section{Uncomplicated inguinal hernia were divided into two groups:}

1. Repair was done by laparoscopic technique.

2. Repair was done by conventional technique.

Criteria for selection of cases:

Patients fulfilling following criteria were included in this study:

1. Patients with sign and symptoms of uncomplicated inguinal hernia, willing for surgery by laparoscopic technique and were fit for general anesthesia.

2. Patients with signs and symptoms of uncomplicated inguinal hernia, willing for surgery by conventional technique and were fit for general anaesthesia.

The criteria for comparison between these two groups were as follows:

1. Stay at Hospital.

2. Post-operative pain and discomfort

Corresponding Author:-Dr. Bhavana Verma.

Address:-Lecturer, department of surgery, S.N.Medical College, Agra, U.P. 
3. Post-operative complications

4. Recurrence rate.

5. Cosmetic results.

This study was done on 90 patients of 0-14 years of age group, coming to surgical ward through surgical outpatient department of S.N. Medical College \& Hospital, Agra.

\section{These patient were divided into two groups:}

\section{Group A -}

Includes 40 patients who underwent laparoscopic hernia repair. Initially the technique used was laparoscopic transabdominal ring closure by purse string sutures with 2-0/3-0 absorbable/non absorbable suture material. This technique was used in all age groups. By this technique we observed recurrence in 3 cases about 20 days interval after repair.

Then by our observation we have changed our technique and divided it into three sub groups according to new technique used for repair:

\section{Subgroup $\mathbf{A}_{1}$ :}

laparoscopic transabdominal ring closure by purse string sutures with 2-0/3-0 absorbable/non absorbable suture material.

Subgroup $\mathbf{A}_{2}$ :

Laparoscopic transabdominal - First the peritonium around the internal ring was incised then 2-3 interrupted stitches with 2-0 ethilon RBN given including the anterior abdominal wall muscles, care was taken not to injure the vas deferens.

\section{Subgroup $\mathbf{A}_{3}$ :}

Laparoscopic transabdominal - First the peritonium around the internal ring was incised, then 1-2 interrupted stitches with 2-0 ethilon RBN the musculofascial wall of anterior abdomen around the internal ring. Finally peritonium was closed by purse string suture.

\section{Group B -}

Includes 50 patients who underwent conventional inguinal hernia repair by simple herniotomy.

\section{Laparoscopic Subgroups:}

1. Subgroup $A_{1:}$ Includes 12 patients, maximum of 0-5 yrs of age group.

2. Subgroup $\mathrm{A}_{2}$ : Includes 23 patients, maximum of 6-10 yrs of age group.

3. Subgroup $\mathrm{A}_{3}$ : Includes 5 patients, maximum of $11-14$ yrs of age group.

4. All patients underwent elective surgery. No obstructed/strangulated case was included in either group.

Overall Comparioson Of Different Variants Between Group A And Group B

\begin{tabular}{|l|l|l|}
\hline Variant & Group -A & Group- B \\
\hline Number of Cases & 40 & 50 \\
\hline Mean Age & $5.60 \pm 1.8$ yrs. (Mean Age $\pm 2 S D)$ & $4.80 \pm 1.6 y r s$. (Mean Age $\pm 2 S D$ ) \\
\hline $\begin{array}{l}\text { Maximum number of cases in Age } \\
\text { group }\end{array}$ & $6-10 y$ yrs 18 cases $=45 \%$ of total & $\begin{array}{l}0-5 \text { years age group 36 cases 72\% of } \\
\text { total }\end{array}$ \\
\hline Sex Ratio & M:F::12.33:1 & M:F::9:1 \\
\hline Right side hernia & 22 & 31 \\
\hline Left side hernia & 11 & 14 \\
\hline
\end{tabular}




\begin{tabular}{|l|l|l|}
\hline Bilateral hernia & 07 & 05 \\
\hline Postoperative Recurrence & $3(7.5 \%$ of total $)$ & $2(4 \%$ of total $)$ \\
\hline Average Duration of operation & $44.5 \mathrm{~min}$ & $35.5 \mathrm{~min}$ \\
\hline Mean Duration of Hospital stay & 1.1 day $\pm 0.35($ mean $\pm 2 \mathrm{SD})$ & 2 days $\pm 0.85($ Mean $\pm 2 \mathrm{SD})$ \\
\hline $\begin{array}{l}\text { Mean Days to Resume Normal } \\
\text { Activity }\end{array}$ & 1.2 days $\pm 0.41($ mean $\pm 2 \mathrm{SD})$ & 2 days $\pm 0.71($ Mean $\pm 2 \mathrm{SD})$ \\
\hline Approximate Blood Loss & $4 \mathrm{ml}$. & $12 \mathrm{ml}$. \\
\hline
\end{tabular}

Comparision Of Average Operative Time Between Group A (Laparoscopic) And Group B (Conventional) Minutes

Average operative time taken in Group A (Laparoscopic repair) is $44.5 \mathrm{~min}$. In Subgroup $A_{1} \quad 25-42 \mathrm{~min}$. Average time taken is $34.5 \mathrm{~min}$.

In Subgroup $\mathrm{A}_{2} \quad 36-51 \mathrm{~min}$. Average time taken is 42.5min.

In Subgroup $A_{3} \quad 43-62$ min. Average time taken is 56.6min.

Average operative time taken in Group B (Conventional repair) is $35.5 \mathrm{~min}$.

So in group A average operative time taken is 1.25 times more than Group B.

Comparision of blood loss (in ml.) In group a and groups

Approximate Blood Loss in Group A was $4 \mathrm{ml}$. and in Group B it was $12 \mathrm{ml}$.

Comparision Of Recurrence Of Hernia Between Group A And Group B

In Group A (Laparoscopic repair) recurrence is seen in 3 cases out of total 40 cases i.e. $7.5 \%$.

In Group B (Conventional repair) recurrence is seen in 2 cases out of total 50 cases i.e. $4 \%$.

Group A (Laparoscopic repair) is subdivided into 3 subgroups according to laparoscopic technique used for repair. In sub group $\mathrm{A}_{1}$ (where trans- abdominal simple ring closure is done) recurrence is seen in 3 cases out of 12 cases i.e. $25 \%$. No. recurrence is seen in subgroup $A_{2}$ and subgroup $A_{3}$

In Group B recurrence was seen in 2 cases of 0-5 yrs of age groups about average 15 days after repair. In $31 / 2$ yrs old male recurrence was seen 13 days after repair. In 1 yr old male recurrence was seen 17 days after repair.

\section{Comparision Of Various Post Operative Complications In Group A And Group B}

In group A (Laparoscopic repair) 8(20\%) patient present with scrotal swelling (due to surgical emphysema in inguino-scrotal region). In Group B (Conventional repair) 19 cases present scrotal swelling which account for 38\%. In group A (Laparoscopic repair) umbilical port burst [due to slipping of knot of monofilament suture] immediately post op period is seen in one case which accounts for $2.5 \%$ while in group B (conventional repair) post operative burst wound (stitch line gap) is seen in 3 cases which account for $6 \%$.

Post operative urinary retention is seen in 2 cases in group A which accounts $5 \%$ while in group B urinary retention is seen in 3 cases i.e.6\%. In group B wound haematoma is seen in 4 cases which accounts for $8 \%$ of cases, while in group A there is no wound haematoma. In Group A - Surgical emphysema over trunk is seen in 2 cases.

\section{Comparision Of Various Post Operative Events Between Group A And Group B}

Mean time to allow patients orally was almost equal in both groups. The criteria to allow patient orally was passage of flatus and presence of normal bowel sound.

Mean time to pass urine after operation was also almost equal in both groups.

Mean requirement of analgesics is much less for Group A than Group B. For Group A it is $1.40 \pm .44$ days (Mean \pm $2 \mathrm{SD}$ ) and for Group $\mathrm{B}$ is $3 \pm .98$ days (Mean $\pm 2 \mathrm{SD}) \mathrm{P}$ value for this is less than $0.02(\mathrm{P}<0.02)$ therefore this comparative data is statistically significant. Mean duration of hospital stay is shorter for Group A than Group B. It is 1.1 days \pm .35 days (mean $\pm 2 \mathrm{SD}$ ) \& for group $\mathrm{B}$ it is $2 \pm .85$ days (mean $\pm 2 \mathrm{SD}) \mathrm{P}$ value for this is less than $.02(\mathrm{P}<$ $.02)$ therefore this comparative data is statistically significant. Group A patients resumed their normal activities much before than Group B patients. For Group A time to resume normal activities is $1.2 \pm .41$ days (Mean $\pm 2 \mathrm{SD}$ ) 
for Group $\mathrm{B}$ is $2 \pm .71$ days (Mean $\pm 2 \mathrm{SD}$ ). $\mathrm{P}$ value for this comparative data is less than $.02(\mathrm{P}<.02)$ therefore it is statistically significant.

\section{Summary:}

Ninety Patients of congenital inguinal hernia (uncomplicated) were included in this study.

Patient of more than 14 yrs age were not undertaken in this study. Maximum patient 50 (55.5\%) were found among 0-5 years of age group, while only 16(1 7.78\%) among 11-14 yrs of age group. 87 patients were male and 3 patients were female, ratio 12.33:1. Mean age group for Group A was 5.60 yrs. (7 months-14 yrs), and for Group B, 4.80 yrs (3 months-14 yrs)

Mean age group for subgroup A, was 2.8 yrs. (7 months-5 yrs), for subgroup $\mathrm{A}_{2}$ and A, it was 7.8 yrs. (6yrs-10 yrs) and 12.2 yrs. (11 yrs-14 yrs) respectively.

Right side of congenital hernias were more common, 55 cases $(61.11 \%)$ than of left side 27 cases $(30 \%)$.

Average operative time was more for Group A patients, i.e.; 44.5 minutes while in Group B it was 35.5 minutes. In group A (Laparoscopic repair) 8 patients suffered from scrotal swelling (due to surgical emphysema in inguinoscrotal region) which account for $20 \%$. While 2 patients with surgical emphysema over trunk.

In group B, 19 cases suffered from scrotal swelling which account for $38 \%$.

1. In group A port side infection was not seen in any cases while in group B stitch line infection was seen in 3 cases and wound haematoma was seen in 4 cases which account for $6 \% \& 8 \%$ respectively. (No wound haematoma was seen in group A patients). -

2. Mean time to allow patients orally after, operation was almost equal in both groups.

3. Group A patients required analgesic for less number of days than Group B patients (1.4 days versus 3 days) post operatively.

4. Hospital stay was shorter for Group A patients in comparison to Group B patients (1.1 days versus 2 days).

5. In Group A patients resumed their normal activities before than Group B Patients (1.2 days versus 2 days).

6. In group A post operative recurrence was seen in 3 cases out of 40 , which account for $7.5 \%$ ( All recurrence were seen in Subgroup $A_{l}$ ).

7. In group B post operative recurrence was seen in 2 cases out of 50 which account for $4 \%$.

\section{Conclusion:-}

1. In our society congenital inguinal hernia is found much more frequently in males then females, ratio $12.33: 1$.

2. Congenital inguinal hernia is more common on right side $(60 \%)$ than left side $(32.5 \%)$.

3. Laparoscopic hernia repair is an evolving procedure not an established one. Awareness of laparoscopic surgery is less popular in our society. So lesser number of patients were ready for repair by this method than conventional method.

4. Laparoscopic hernia repair is performed as a day case procedure. Laparoscopic hernia repair takes more operative time, may be because of learning curve.

5. Following laparoscopic hernia repair, patients require lesser analgesic for fewer number of days. Laparoscopic hernia repair offers minimal post operative complications, and shorter hospital stay in comparison to conventional repair. Laparoscopic hernia repair offers rapid return to full activity in comparison to conventional repair.

6. Laparoscopic hernia repair can be performed safely at the time of Laparoscopy for other procedure and also during laparoscopic hernia repair we can find other anomalies.

7. For recurrence the technique is not preferable than open technique for inexperience hands.

8. Laparoscopic congenital hernia repair is an effective method to correct inguinal hernia. Laparoscopic hernia repair is easy for experienced Laparoscopist. Bilaterality is of no concern, cosmesis is superb. 